\title{
Obesity and weight change related to parity and breast-feeding among parous women in Brazil
}

\author{
Denise C Coitinho' ${ }^{1}$, Rosely Sichieri ${ }^{2, *}$ and Maria Helena D'Aquino Benício ${ }^{3}$ \\ 'Department of Nutrition, University of Brasília, Brazil: ${ }^{2}$ Social Medicine Institute, State University of Rio de Janeiro, \\ Brazil: ${ }^{3}$ Department of Nutrition, Public Health Faculty, University of São Paulo, Brazil
}

Submitted 20 June 2000: Accepted 9 January 2001

\begin{abstract}
Objective: Studies on the independent role of parity in long-term body weight change in economically developing countries are scarce and inconclusive, and only a few studies have taken into account patterns of breast-feeding. This association was examined in a national cross-sectional survey representative of Brazilian parous women.

Design and setting: The survey conducted in 1996 measured women's height and weight in the household and data on weight prior to the first pregnancy, parity and breast-feeding were recalled.

Subjects: A sample of 2338 parous women, 15 to 49 years of age, 29 months after last delivery on average, had current body mass index (BMI, in $\mathrm{kg} \mathrm{m}^{-2}$ ) modelled through hierarchical multiple linear regression analysis. Explanatory variables included parity, days of predominant breast-feeding, BMI pre-pregnancy, socioeconomic, geographic, demographic and other reproductive variables.

Results: Prevalences of overweight $\left(\mathrm{BMI}=25.0-29.9 \mathrm{~kg} \mathrm{~m}^{-2}\right)$ and obesity $(\mathrm{BMI} \geq$ $30.0 \mathrm{~kg} \mathrm{~m}^{-2}$ ) were $25.2 \%$ and $9.3 \%$. The overall mean weight gain per year after the first pregnancy was $0.90 \mathrm{~kg}$ for an average time since first pregnancy of eight years. BMI pre-pregnancy modified the association between current BMI and parity. Therefore, weight change attributed to parity calculated for a woman of average height $(1.56 \mathrm{~m})$ was $0.60 \mathrm{~kg}$ greater for primiparous women with a BMI pre-pregnancy of $30 \mathrm{~kg} \mathrm{~m}^{-2}$, compared with women with BMI pre-pregnancy of $25 \mathrm{~kg} \mathrm{~m}^{-2}$. This greater weight retention among obese women was $1.21 \mathrm{~kg}$ for women with two children and $1.82 \mathrm{~kg}$ for women with three or more children. Parity reduced the effect of weight loss associated with lactation $(1.75 \mathrm{~kg}$ for six months of lactation among primiparous women and $0.87 \mathrm{~kg}$ among women with three or more children). For the sub-sample of 793 primiparous women, a weight decrease of $300 \mathrm{~g}$ was associated with each month of predominant breast-feeding for all prior BMI levels.

Conclusions: In this study, weight change associated to reproduction was highly dependent on BMI previous to pregnancy and the effects of parity and lactation were small.
\end{abstract}

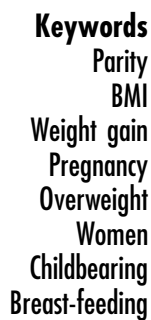

Prevalence of overweight and obesity is high in most of the economically developed world and is increasing in developing countries ${ }^{1}$. In Brazil the prevalence of overweight/obesity has increased sharply in the last two decades, particularly among women of reproductive age. Nation-wide nutritional surveys have shown a $20 \%$ increase in the prevalence of obesity for parous women aged 15 to 49 years from 1989 to $1996^{2}$.

Reproductive factors, especially parity, have been positively associated with weight gain and the onset of obesity in population-based studies in developed countries $^{3-10}$. The extent of this relationship and the pathways leading to the parity-associated weight gain in the different populations are, however, yet to be understood.
Only one study has investigated this relationship for the developing world ${ }^{11}$, and it showed that two or more pregnancies significantly increased the risk of overweight.

We studied, in a nation-wide population-based sample in Brazil, the cross-sectional association of body weight with parity and breast-feeding.

\section{Population and methods}

\section{Study population}

The III Brazilian Demographic and Health Survey (DHS96) was conducted in 1996. Weight and height were measured in a national representative sample of parous women. For the specific purpose of assessing the 
relationship between reproduction and weight gain in Brazil, these women were also asked to recall their weight prior to the first pregnancy. A full description of the DHS96 sampling frame can be found elsewhere ${ }^{12}$. In short, it used a two-stage probability sampling of all regions of the country, urban and rural areas, except for the rural North region. Response rate for households was $80.9 \%$ and 14,252 households were visited.

The eligible population for the current analysis was the 3761 parous women with one or more children under five years of age, as anthropometric data were collected for these women only. Exclusions included women pregnant at the time of the survey (285 women); history of multiple births ( 59 women); last delivery six months or less prior to the interview ( 469 women); first birth before the age of 15 (73 women) (as they could have gained height since their first pregnancy, interfering with the calculations of the prior body mass index (BMI)); and 537 women who had missing values for their weight before first pregnancy. The final study sample size was 2338 women. From these women, 793 were primiparous and further analysis of this group was carried out.

\section{Measurement of the variables}

The dependent variable BMI (weight/height ${ }^{2}$, in $\mathrm{kg} \mathrm{m}^{-2}$ ) was calculated from measurements of weight and height taken in the household by two trained interviewers. At the end of the 30-minute interview, women were asked to recall their weight before first pregnancy.

SECA-UNICEF 890 micro-electronic scales with lithium batteries and STANLEY anthropometric tapes were used. Techniques were standardised and interviewers were selected on the basis of their precision. Quality control was carried out during fieldwork supervision. Technical errors of measurement were equal to $20 \mathrm{~g}$ for weight and $0.23 \mathrm{~cm}$ for height. The women wore light clothes and no shoes.

Parity is the number of live births and stillbirths of each woman and lactation is days of predominant breastfeeding. For multiparous women the average lactation value per child was calculated from their different lactation experiences.

Purchasing power score, as used by the Brazilian Association of Marketing Research, is a combined score of highest level of education obtained by the family with services and items available in the house, such as housemaid, number of radios, video cassette recorders, televisions, refrigerators, etc. Families were categorised into five levels. The regions of the country were combined in two categories: North/Northeast, which is the less developed part of the country, and the three other regions together (South, Southeast and Midwest).

\section{Analytical procedures}

The Brazilian DHS-96 survey used a complex sample design requiring adjustment for design effects of cluster sample, performed using STATA software. All means or percentages are weighted to reflect national estimates. Multiple linear regressions used the forward chunk wise method that incorporates the hierarchical conceptual framework analysis ${ }^{13}$. At the first stage socio-economic/ geographic variables were regressed on current BMI. Modelling progressed with the inclusion of the demographic variables (chunk 2), previous BMI (chunk 3) and reproductive variables (chunk 4). At the end of the fourth step, all biologically plausible interactions between the co-variables and parity, including parity $\times$ lactation (first model), and between the co-variables and lactation (second model) were tested jointly. Second-order terms were tested for age, parity and breast-feeding. Exclusion criterion for interaction was $P>0.05$ and for keeping variables in the model it was $P>0.10$, starting with the least significant variable. The two final models were diagnosed for the linear regression assumptions, influential cases and collinearity.

An additional analysis, with similar modelling, considered only primiparous women in order to elucidate the role of lactation independent of parity.

\section{Results}

The prevalence of overweight $\left(\mathrm{BMI}=25.0-29.9 \mathrm{~kg} \mathrm{~m}^{-2}\right.$ ) and obesity $\left(\mathrm{BMI} \geq 30.0 \mathrm{~kg} \mathrm{~m}^{-2}\right.$ ) increased from $11.5 \%$ and $1.7 \%$ before the first pregnancy to $25.2 \%$ and $9.3 \%$, respectively. Overall mean weight gain after first pregnancy, for the period of $8(7.7-8.2)$ years since first pregnancy and the interview, was 0.9 (0.8-1.0) $\mathrm{kg}$ per year.

Mean BMI and the prevalence of overweight and obesity increased with parity $(P<0.05)$, but the association with breast-feeding was not significant (Table 1). Prior overweight and prior obesity rates did not differ among parity groups, but less educated women, with lower purchasing power, living in a rural area or in the North/Northeast region were more likely to have three or more children (Table 1). Women with the higher parities were also more likely to be mulatto or black.

Most of the association of parity with BMI was due to the confounding effect of age, but women with only one child had lower age-adjusted prevalence of overweight and obesity than women with two or more children (data not shown).

Table 2 shows regression coefficients $(\beta)$ and multiple correlation coefficients $\left(R^{2}\right)$ from a sequence of regression models of BMI on (1) socio-economic/geographic, (2) demographic, (3) previous BMI and (4) reproductive variables. The final model explained $32 \%$ of the variance of current BMI. At the first stage of modelling, region of residence and education stayed in the model for adjustment for the next chunk of demographic variables. Age was kept from the second stage. Previous BMI increased the model's explanatory capacity by $27.5 \%$ 
Table 1 Means $^{\star}$ and prevalences* of risk factors for overweight by categories of parity, DHS Brazil 1996 sub-sample of 2338 parous women

\begin{tabular}{|c|c|c|c|}
\hline \multirow[b]{2}{*}{ Variable } & \multicolumn{3}{|c|}{ Parity category } \\
\hline & $\begin{array}{l}\text { One child } \\
(n=793)\end{array}$ & $\begin{array}{l}\text { Two children } \\
\quad(n=743)\end{array}$ & $\begin{array}{l}\text { Three or more children } \\
\qquad(n=802)\end{array}$ \\
\hline Current age (years) (mean) & $24.4^{\mathrm{a}}$ & $28.3^{\mathrm{b}}$ & $32.0^{\mathrm{C}}$ \\
\hline Current BMI (kg m$\left.{ }^{-2}\right)$ (mean) & $23.3^{\mathrm{a}}$ & $24.2^{\mathrm{b}}$ & $24.6^{\mathrm{b}}$ \\
\hline Overweight $\left(\mathrm{BMI}=25.0-29.9 \mathrm{~kg} \mathrm{~m}^{-2}\right)(\%)$ & $23.0^{\mathrm{a}}$ & $25.0^{\mathrm{b}}$ & $25.7^{c}$ \\
\hline Obese $\left(\mathrm{BMI} \geq 30.0 \mathrm{~kg} \mathrm{~m}^{-2}\right)(\%)$ & $5.8^{\mathrm{a}}$ & $9.3^{\mathrm{b}}$ & $8.4^{\mathrm{c}}$ \\
\hline Age at birth of first child (years) (mean) & $22.4^{\mathrm{a}}$ & $22.1^{\mathrm{a}}$ & $19.9^{c}$ \\
\hline Previous BMI ( $\left.\mathrm{kg} \mathrm{m}^{-2}\right)$ (mean) & 21.8 & 21.6 & 21.6 \\
\hline Previously overweight $\left(\mathrm{BMI}=25.0-29.9 \mathrm{~kg} \mathrm{~m}^{-2}\right)(\%)$ & 11.6 & 8.8 & 12.9 \\
\hline Previously obese $\left(\mathrm{BMI} \geq 30.0 \mathrm{~kg} \mathrm{~m}^{-2}\right)(\%)$ & 1.5 & 1.9 & 1.7 \\
\hline Time since last birth (months) (mean) & $27.2^{\mathrm{a}}$ & $29.6^{\mathrm{b}}$ & $30.9^{\mathrm{b}}$ \\
\hline Predominant breast-feeding (days) (mean per child) & 50.4 & 46.2 & 43.7 \\
\hline Proportion of urban population (\%) & $89.1^{\mathrm{a}}$ & $81.6^{a}$ & $75.7^{\mathrm{c}}$ \\
\hline \multicolumn{4}{|l|}{ Region } \\
\hline South+Southeast+Midwest (\%) & $56.1^{\mathrm{a}}$ & $57.6^{\mathrm{a}}$ & $40.5^{\mathrm{c}}$ \\
\hline North+Northeast (\%) & 43.9 & 42.4 & 59.4 \\
\hline \multicolumn{4}{|l|}{ Class of purchasing power } \\
\hline $\mathrm{A}+\mathrm{B}(\%)$ (higher) & $14.5^{\mathrm{a}}$ & $8.8^{\mathrm{b}}$ & $2.9^{\mathrm{C}}$ \\
\hline $\mathrm{C}(\%)$ & 28.8 & 27.3 & 10.5 \\
\hline $\mathrm{D}(\%)$ & 36.5 & 33.6 & 31.6 \\
\hline E (\%) (lower) & 20.1 & 30.2 & 54.9 \\
\hline \multicolumn{4}{|l|}{ Education } \\
\hline 0 years $(\%)$ & $0.4^{\mathrm{a}}$ & $2.1^{\mathrm{b}}$ & $11.1^{\mathrm{c}}$ \\
\hline 1 to 4 years $(\%)$ & 22.0 & 31.6 & 45.8 \\
\hline 5 to 8 years $(\%)$ & 31.7 & 33.7 & 31.2 \\
\hline 9 years or more $(\%)$ & 45.8 & 32.5 & 11.9 \\
\hline \multicolumn{4}{|l|}{ Ethnic group } \\
\hline White (\%) & $44.9^{\mathrm{a}}$ & $42.4^{\mathrm{a}}$ & $27.5^{\mathrm{c}}$ \\
\hline Mulatto (\%) & 51.2 & 53.9 & 67.4 \\
\hline Black (\%) & 3.9 & 3.6 & 5.1 \\
\hline
\end{tabular}

* Values with different letters are significantly different $(P<0.05)$.

(partial $R^{2}$ ). At the fourth stage, reproductive variables and interactions were included in the model. Significant interaction terms were previous BMI $\times$ parity $(P=0.02)$ and predominant breast-feeding $\times$ parity $(P=0.05)$. Combined effects of parity and breast-feeding are shown in Fig. 1. For clarity of presentation, the predictive values of weight change attributed to breast-feeding were calculated for a woman of average height $(1.56 \mathrm{~m})$. Parity

Table 2 Sequence of multivariate linear regression models of BMI on (1) socio-economic/geographic, (2) demographic, (3) previous $\mathrm{BMI}$ and (4) reproductive variables*, among 2338 women from the III Demographic and Health Survey, Brazil 1996

\begin{tabular}{lcccc}
\hline Variable & $\beta$ & $P$ & Model & $R^{2}$ \\
\hline Region (Others $\times$ North/Northeast) & -0.52 & 0.008 & 1 & \\
Years of education (four categories) & -0.12 & 0.25 & 1 & 0.003 \\
Age (continuous) & 0.13 & $<0.001$ & 2 & \\
Previous BMl (continuous) & 0.85 & $<0.001$ & 3 & 0.29 \\
Age at birth of first child (continuous) & -0.04 & $<0.001$ & 4 & \\
Time since last birth (continuous) & 0.01 & 0.004 & 4 & \\
Breast-feeding (days, continuous) & -0.005 & 0.03 & 4 & \\
Parity (continuous) & 0.95 & 0.04 & 4 & \\
Previous BMI $\times$ parity & -0.05 & 0.02 & 4 & \\
Breast-feeding $\times$ parity & 0.001 & 0.05 & 4 & 0.32 \\
\hline
\end{tabular}

* (1) Socio-economic/geographic variables (geographic region of residence, urban/rural area of residence, purchasing power score - A, B, C, D or E and years of education); (2) demographic variables (current age, age squared and ethnic group); (3) previous BMI; (4) reproductive variables (age at birth of first child, time since last birth, days of predominant breastfeeding, parity and interactions). reduces the effect of weight loss associated with lactation and the overall effect of lactation was small $(1.75 \mathrm{~kg}$ for six months of lactation among primiparous women and $0.87 \mathrm{~kg}$ among women with three or more children). The interaction between parity and BMI shown in Table 2 refers to a weight retention of $0.60 \mathrm{~kg}$ for women with a BMI pre-pregnancy of $30 \mathrm{~kg} \mathrm{~m}^{-2}$, after the first child born, compared to women with a BMI pre-pregnancy of $25 \mathrm{~kg} \mathrm{~m}^{-2}$. This weight excess is $1.21 \mathrm{~kg}$ for two children and $1.82 \mathrm{~kg}$ for three or more children.

Models for primiparous women, for whom recalled information on breast-feeding practices is supposed to be more precise, are shown in Table 3. From the first chunk of socio-economic variables, only region of residence was kept in the model. Previous BMI increased the model's explanatory capacity by $43 \%$ and was kept in the final model with time since last birth and lactation. No interactions were observed and the final model explained $48 \%$ of the variation of current BMI. Based on this model, a weight decrease of almost $300 \mathrm{~g}$ was observed for each month of predominant breast-feeding. Therefore, for both primiparous and multiparous models, weight loss associated with exclusive lactation of the first child was about the same.

Graphical analysis of the model's residuals did not show violations in the linear regression assumptions of normality, independence or homoskedasticity. Influential points - 17 cases for the first model and 22 cases for 


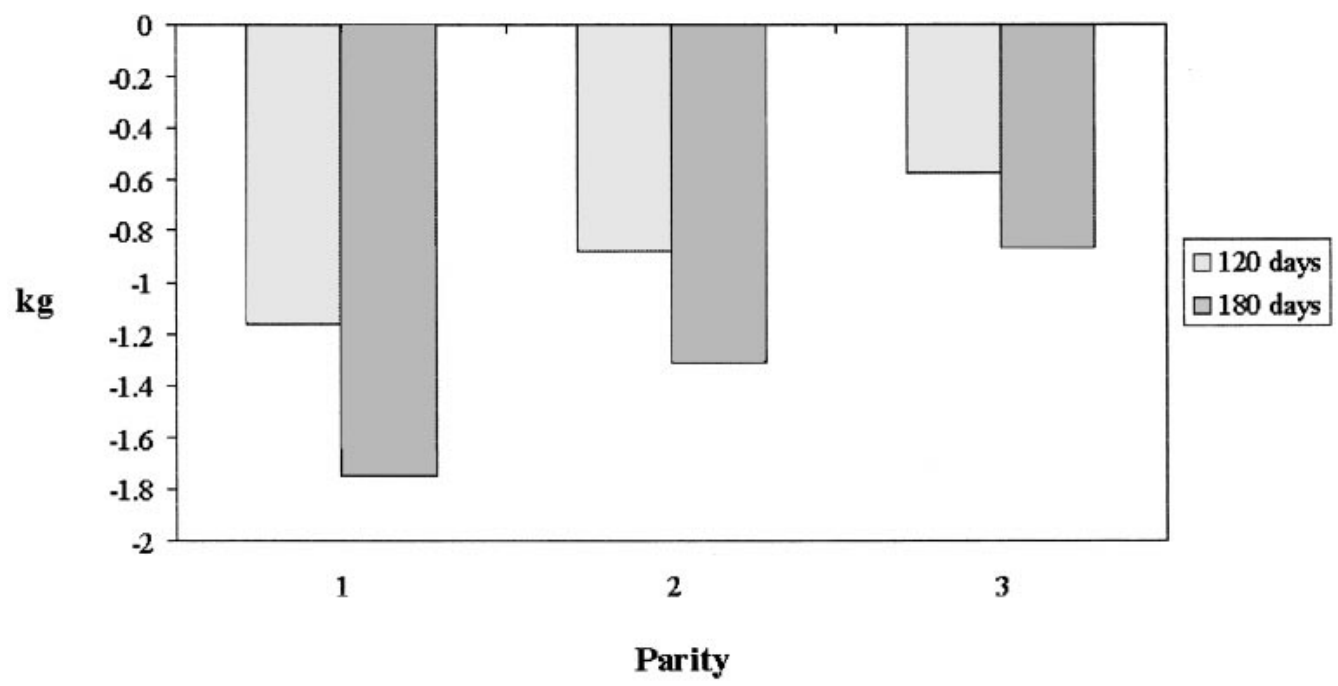

Fig. 1 Weight loss associated with lactation duration by parity

the second - were identified and considered plausible; and when models were examined without these influential cases coefficients were almost identical. Collinearity was also tested through the analysis of variance inflation factors and was not observed in the models prior to the inclusion of interaction terms. With interactions in the first model, minimal collinearity was found, as expected ${ }^{13}$.

An attempt to validate the recalled pre-pregnancy weight was made by comparing the recalled BMI distribution of the 21- to 29-year-old women in our study sample with a measured BMI distribution of nulliparous women 15 to 23 years old from a previous national representative survey carried out in Brazil in 1989. The recalled weight of our sub-sample corresponds approximately to nulliparous women in the 1989 survey. Good consistency was observed in the percentile distributions of mean BMI for each three-year interval with the following means (standard deviation, SD, in parentheses): $21.2( \pm 2.7), 21.8( \pm 3.0)$ and $21.7( \pm 3.5)$ for 1989 and $21.8( \pm 3.2), 21.9( \pm 3.1)$ and $21.0( \pm 3.7)$ for 1996. Prevalence of $\mathrm{BMI}<20.0 \mathrm{~kg} \mathrm{~m}^{-2}$ and $\mathrm{BMI} \geq$

Table 3 Sequence of multivariate linear regression models of BMI on (1) socio-economic/geographic, (2) demographic, (3) previous BMI and (4) reproductive variables*, among 793 primiparous women from the III Demographic and Health Survey, Brazil 1996

\begin{tabular}{lrccc}
\hline Variable & $\beta$ & $P$ & Model & $R^{2}$ \\
\hline Region (Others $\times$ North/Northeast) & -0.83 & $<0.001$ & 1 & 0.01 \\
Previous BMl (continuous) & 0.83 & $<0.001$ & 3 & 0.44 \\
Age at birth of first child (continuous) & 0.02 & 0.003 & 4 & \\
Time since last birth (continuous) & 0.02 & $<0.001$ & 4 & \\
Breast-feeding (days, continuous) & -0.004 & 0.04 & 4 & 0.48 \\
\hline
\end{tabular}

* (1) Socio-economic/geographic variables (geographic region of residence, urban/rural area of residence, purchasing power score - A, B, C, D or E and years of education); (2) demographic variables (current age, age squared and ethnic group); (3) previous BMI; (4) reproductive variables (age at birth of first child, time since last birth, days of predominant breastfeeding, parity and interactions).
$30.0 \mathrm{~kg} \mathrm{~m}^{-2}$ based on recalled weight in 1996 were 31.8 and 1.7 , which were $5.0 \%$ and $5.8 \%$ lower than the prevalence based on measured BMI in 1989.

The 537 women excluded from this study due to missing information for previous weight were significantly poorer and shorter, but their current mean BMI did not differ from the group with complete information (data not shown).

\section{Discussion}

We found that, in 1996, 25.2\% of Brazilian parous women were overweight and $9.3 \%$ were obese. This indicates a need for immediate attention and management of female overweight and obesity in Brazil as an increasingly serious public health problem. Besides being a risk factor for many chronic diseases, female excess weight is associated with impaired psychological health, expressed as low self-esteem, body dissatisfaction, depression and eating disorders ${ }^{1}$.

The mean weight gain of Brazilian primiparous women of $900 \mathrm{~g} \mathrm{year}^{-1}$ is in the range of weight increase in studies from developed countries, the values of which vary from $0.35 \mathrm{~kg}_{\text {year }}{ }^{-1}$ to $1.5 \mathrm{~kg}$ per year ${ }^{7,10,14,15}$.

Reproduction is considered an important determinant of weight gain during a woman's life and this study has attempted to estimate how much of the weight change after pregnancy could be attributed to parity and breastfeeding taking into account the weight pre-pregnancy. Many studies have estimated parity-related weight increase $^{3,4,5,7,10,14-24}$, but only a few studies $4,5,10,14,15,18,24$ have made an analysis adjusted for previous BMI, an important and recommended methodological step ${ }^{20,21}$. In addition, weight change related to parity is dependent on the effect of lactation, but results of the effect of lactation on weight retention after pregnancy have been inconclusive ${ }^{25}$. 
We found that pre-pregnacy BMI was the most important predictor of recent BMI, both in primiparous as well as multiparous women, with lean women having small overall weight gain. Consistent with this finding, a US-based population follow-up analysis (NHANES I follow-up) showed that women with high BMI had increased risk of greater weight gain with parity ${ }^{3}$.

Two studies evaluated the interaction between lactation and parity, but they did not control for previous BMI, and the results were contradictory. One ${ }^{22}$ suggested that breast-feeding was a protective factor for parity-related weight retention and the other ${ }^{16}$ found no association.

Important variations in diet and physical activity associated with pregnancy and lactation may explain these differences in the literature. In addition, women showed differences of a factor of eight in resting metabolic rate associated with pregnancy ${ }^{26}$. As a consequence Pitkin $^{27}$ stated that the 'one size fits-all' assumption should be avoided in relation to the energy needs of pregnant women.

Our study contributes to the understanding of this variability by showing the important interaction between weight previous to any pregnancy with parity and between parity and lactation. Women who started their reproductive lives with normal weight $\left(\mathrm{BMI}=25 \mathrm{~kg} \mathrm{~m}^{-2}\right.$ ) gained less weight than women with higher BMI at baseline. We found also a small effect of lactation on the weight change, which is reduced further with increased parity $(1.75 \mathrm{~kg}$ reduction for six months of lactation among primiparous women and $0.87 \mathrm{~kg}$ reduction among women with three or more children). An 18-month follow-up study of 110 American women after parturition also found a reduction of less than $2 \mathrm{~kg}$ between bottlefeeding and infants weaned at six to 12 months ${ }^{28}$. Other studies found that lactation was associated with weight gain $^{16-19}$. Our modelling based on primiparous women showed consistent results, with each month of predominant breast-feeding corresponding to $300 \mathrm{~g}$ of weight reduction, even counterbalancing the effect of age of $330 \mathrm{~g}$ of weight increase per year.

Recall bias of weight in our study probably did not explain our findings, since great consistency was shown in comparisons of recalled BMI distribution of a subsample of 23- to 29-year-old women and a measured BMI distribution of a set of nulliparous women aged 15 to 21 years from a previous national representative survey carried out in Brazil in 1989.

Encouragement of breast-feeding is a priority public health measure in Brazil due to its positive impact on child health. However, the results of this study indicate that lactation has a negligible role, particularly among multiparous, overweight women, in the reduction of obesity. As a consequence, public health services should consider tailoring the recommendations for breast-feeding in order to prevent the development of obesity among lactating women.

\section{References}

1 World Health Organization. Obesity, Preventing and Managing the Global Epidemic. Report of a WHO Consultation on Obesity. Geneva: WHO/NUT/NCD/98.1, 1998.

2 Coitinho DC. A influência da história reprodutiva no índice de massa corporal de mulheres Brasileiras [The influence of reproductive history in the body mass index of Brazilian women]. Ph.D. dissertation. Brazil: Public Health School, University of São Paulo, 1998.

3 Wolf WS, Sobal J, Olson CM, Frongillo EA. Parity-associated body weight: modification by socio-demographic and behavioral factors. Obes. Res. 1997; 5(2): 131-41.

4 Smith DE, Lewis CE, Caveny JL, et al. Longitudinal changes in adiposity associated with pregnancy - the CARDIA study. JAMA 1994; 271(22): 1747-51.

5 Williamson DF, Serdula MK, Liu S, et al. A prospective study of childbearing and 10-year weight gain in the U.S. white women 25 to 45 years of age. Int. J. Obes. 1994; 18: 561-9.

6 Parker J, Abrams B. Differences in postpartum weight retention between black and white mothers. Obstet. Gynaecol. 1993; 81(5): 768-74.

7 Brown JE, Kaye AS, Folsom AR. Parity related weight change in women. Int. J. Obes. 1992; 16: 627-31.

8 Newcomb RG. Development of obesity in parous women. $J$. Epidemiol. Comm. Health 1982; 36: 306-9.

9 Heliovaara M, Aromaa A. Parity and obesity. J. Epidemiol. Comm. Health 1981; 35: 197-9.

10 Ohlin A, Rossner S. Maternal body weight development after pregnancy. Int. J. Obes. 1990; 14: 159-73.

11 Arroyo P, Avila-Rosas H, Fernandez V, Casanueva E, Galvan D. Parity and the prevalence of overweight. Int.J. Gynaecol. Obstet. 1995; 48: 269-72.

12 Sociedade Civil do Bem Estar Familiar. Pesquisa Nacional sobre Demografia e Saúde - DHS/III. Rio de Janeiro, Brazil: BEMFAM e MACRO International, 1997.

13 Kleinbaum DG, Kupper LL, Muller KE, Nizan A. Applied Regression Analysis and Other Multivariable Methods, 3rd revised edn. New York, NY: Brooks/Cole Publishing Company, 1998.

14 Greene GW, Smiciklas WH, Scholl TO, Karp RJ. Post partum weight change: how much of the weight gained in pregnancy will be lost after delivery? Obstet. Gynaecol. 1988; 71: 701-7.

15 Hunt SC. Pregnancy weight retention in morbid obesity. Obes. Res. 1995; 3(2): 121-30.

16 Rookus MA, Rokebrand P, Burema J, Deurenberg GP. The effect of pregnancy on the body mass index 9 months postpartum in 49 women. Int. J. Obes. 1987; 11: 609-18.

17 Shauberger CW, Rooney BL, Brimer LM. Factors that influence weight loss in the puerperium. Obstet. Gynaecol. 1992; 79: 424-9.

18 Potter S, McFarlin B, Campbell E, et al. Does infant feeding method influence maternal postpartum weight loss? J. Am. Diet. Assoc. 1991; 91(4): 441-5.

19 Dugdale AE, Eaton-Evans J. The effect of lactation and other factors on post-partum changes in body-weight and triceps skinfold thickness. Br. J. Nutr. 1989; 61: 149-53.

20 French SA. Predictors of weight change over two years among a population of working adults: the Healthy Worker Project. Int. J. Obes. 1994; 18: 145-54.

21 Institutes of Medicine. Nutrition During Pregnancy: Weight Gain, Nutrient Supplements. Washington, DC: National Academy Press, 1990.

22 Dewey KG, Heining MJ, Laurei NA. Maternal weight-loss patterns during prolonged lactation. Am. J. Clin. Nutr. 1993; 58: $162-6$.

23 Tavani A, Negri E, La Vecchia C. Determinants of body mass index: a study from northern Italy. Int. J. Obes. Relat. Metab. Disorders 1994; 8: 497-502. 
24 Rush D, Lumey LH, Ravell ACJ, Myers B. The indirect association between lactation with subsequent perimenopausal body weight. Eur. J. Clin. Nutr. 1996; 50(1): 12-16.

25 Dorea JG. Changes in body weight and adiposity during lactation. Nutr. Res. 1997; 17: 379-89.

26 Koop-Hoolihan LE, Van Loan MD, Wong WW, King JC.
Longitudinal assessment of energy balance in well-nourished pregnant women. Am. J. Clin. Nutr. 1999; 69: 697-704.

27 Pitkin RM. Energy in pregnancy. Am. J. Clin. Nutr. 1999; 69 583-4.

28 Janney CA, Zhang D, Sowers M. Lactation and weight retention. Am. J. Clin. Nutr. 1997; 66: 1116-24. 